\title{
ChemComm
}

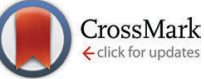

Cite this: Chem. Commun., 2015, 51, 10194

Received 27th March 2015, Accepted 14th May 2015

DOI: $10.1039 / \mathrm{c} 5 \mathrm{cc} 02550 \mathrm{~h}$

www.rsc.org/chemcomm

\section{Direct accessibility of mixed-metal (III/II) acid sites through the rational synthesis of porous metal carboxylates $\dagger$}

\author{
S. Wongsakulphasatch, ${ }^{a b}$ F. Nouar, ${ }^{* a}$ J. Rodriguez, ${ }^{c}$ L. Scott, ${ }^{a}$ C. Le Guillouzer, ${ }^{d}$ \\ T. Devic, ${ }^{a}$ P. Horcajada, ${ }^{a}$ J.-M. Grenèche, ${ }^{e}$ P. L. Llewellyn, ${ }^{c}$ A. Vimont, ${ }^{d}$ G. Clet, ${ }^{d}$ \\ M. Daturi ${ }^{d}$ and C. Serre*a
}

The scalable and environmentally-friendly synthesis of mixed $\mathrm{Fe}($ III)/ $M($ II) ( $M=\mathrm{Ni}, \mathrm{Co}, \mathrm{Mg}$ ) polycarboxylate porous MOFs based on the Secondary Building Unit approach is reported. A combination of in situ infrared spectroscopy, ${ }^{57} \mathrm{Fe}$ Mössbauer spectrometry and adsorption microcalorimetry confirms the direct accessibility of the iron(III) and metal(II) sites under low temperature activation conditions.

Due to their chemical and structural diversity, Metal-Organic Frameworks (MOFs) or Porous Coordination Polymers (PCPs) are an attractive class of porous crystalline materials. They have been evaluated for a wide range of potential applications, ranging from gas storage, separation, catalysis, sensing to biomedicine. ${ }^{1}$ Among the thousands of architectures reported so far, only a few of them are considered suitable for practical applications. ${ }^{2}$ It is indeed challenging to combine high porosity with sufficient chemical stability, scalability of the synthesis and desired chemical functionality. Iron(III) polycarboxylate MOFs are particularly attractive candidates due to their robustness, their high biocompatibility and their redox behaviour. Their potential interest in separation, ${ }^{3}$ catalysis $^{4}$ or drug delivery ${ }^{5}$ has recently been confirmed. Typical examples are the series of highly flexible MIL- $53^{6}$ or MIL-88, ${ }^{7}$ the highly porous MIL-100, ${ }^{8}$ MIL- $101^{9}$, PCN-53, ${ }^{10}$ MIL- $127^{4 a}$ (or socMOF) and a BTB based solid with the topology ${ }^{11}$ or the porphyrin based iron MOFs MIL- $141^{12}$ or PCN-600. ${ }^{13}$ Their functionalization

\footnotetext{
${ }^{a}$ Institut Lavoisier (CNRS UMR 8180), Université de Versailles St-Quentin en Yvelines, 45 avenue des Etats-Unis, 78035 Versailles Cedex, France. E-mail: farid.nouar@uvsq.fr, christian.serre@uvsq.fr

${ }^{b}$ Department of Chemical Engineering, Faculty of Engineering and Industrial Technology Silpakorn University, Nakhon Pathom 73000, Thailand ${ }^{c}$ Aix-Marseille Univ., CNRS, Laboratoire MADIREL (UMR 7246), Campus de Saint Jérôme, 13397, Marseille Cedex 20, France

${ }^{d}$ Laboratoire Catalyse et Spectrochimie, ENSICAEN, Université de Caen Basse-Normandie, CNRS, 6 Bd Maréchal Juin, 14050 Caen, France ${ }^{e}$ Institut des Molécules et des Matériaux du Mans (CNRS UMR 6283), Université du Maine, 72085 Le Mans, France

$\dagger$ Electronic supplementary information (ESI) available: Detailed synthesis and activation; X-ray powder diffraction; TGA; infrared, energy-dispersive X-ray and Mössbauer spectroscopies; $\mathrm{N}_{2}, \mathrm{CO}_{2}$ and CO sorption isotherms. See DOI: 10.1039/ c5cc02550h
}

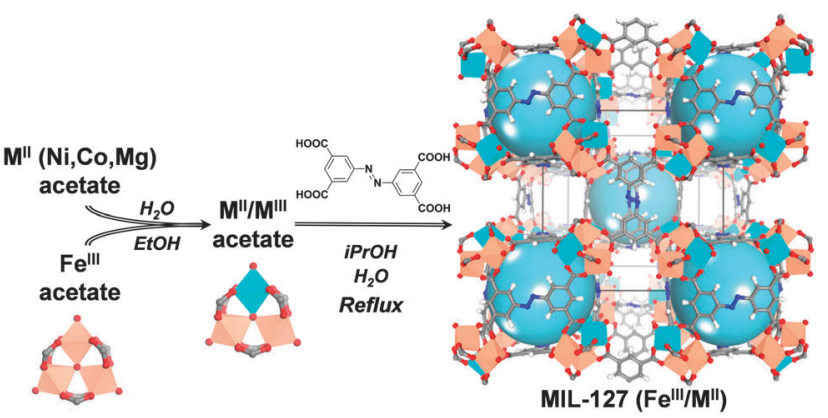

Fig. 1 Schematic representation of the building block approach to produce mixed-metal carboxylate MOFs such as MIL-127. From left to right, mixing iron acetate trimeric building blocks with $M^{\prime \prime}$ acetate compounds leads to neutral mixed-metal trimeric building blocks that are used to produce the titled MOF via acetate/ligand exchange.

(direct or via post-synthetic grafting) or the isoreticular concept allows a careful tuning of their structural or chemical features. Few of these solids ${ }^{4 a, 7-13}$ are built up from oxo-centered trimers of iron(III) octahedra (Fig. 1, left), which act as accessible metallic $\mathrm{Fe}(\mathrm{III})$ sites upon solvent departure. It is noteworthy that at a rather high activation temperature $(T>473 \mathrm{~K})$ under vacuum or inert gas flow, it is possible to partially and reversibly reduce such sites. This leads to mixed valence iron(III/II) MOFs, the concomitant presence of $\mathrm{Fe}(\mathrm{III})$ and $\mathrm{Fe}(\mathrm{II})$ Lewis acid sites resulting in enhanced properties in separation, biomedicine or catalysis. ${ }^{3 b}$

An alternative method for the synthesis of mixed-valence oxo-trimer based MOFs consists in substituting, in a controlled manner, some of the constitutive iron(III) cations by other octahedrally coordinated metal cations to have a direct access to two valence states i.e., without requiring harsh activation conditions. Strategies to obtain mixed metal cation based solids have already been applied in MOF chemistry but in most cases consisted in (i) associating different cations of the same charge within the same building unit or (ii) cations of different charges but with different coordination numbers. ${ }^{14}$ Post-synthetic modification, such as metalation, is another attractive way to build mixed-metal materials, but this method suffers from a lack of control of the 
stoichiometry between the two different cations. ${ }^{15}$ However, if one attempts to prepare a mixed valence MOF from a direct mixture of iron(III) and metal(II) precursors, one would face the difficulty to prepare materials with the right architecture and a controlled iron(III)/metal(II) ratio. Besides, an elegant method to reach a higher degree of control of the synthesis consists in the use of pre-defined secondary building units (SBUs) to design porous solids with a controlled architecture. This method was previously reported for the design of porous iron(III) dicarboxylate MOFs (MIL-88s) ${ }^{7,16}$ or zirconium(Iv) dicarboxylate solids (UiO-66's). ${ }^{17}$ It was proven that the structural integrity of the molecular building blocks was retained throughout the synthesis. ${ }^{18}$ Here, using oxocentered trimeric mixed iron(III)/metal(II) acetates ( $\mathrm{M}=\mathrm{Co}, \mathrm{Ni}, \mathrm{Mg}$ ) as building blocks, we report the scalable and green preparation of mixed-metal MOFs and show how it strongly impacts the accessibility of their Lewis acid sites. To illustrate our concept, we first applied this method to the rigid microporous iron(III) azobenzenetetracorboxylate MIL-127 or soc-MOF ${ }^{19,4 a}$ (Fig. 1). This solid with general formula $\mathrm{Fe}_{3} \mathrm{O}\left(\mathrm{C}_{12} \mathrm{~N}_{2} \mathrm{H}_{6}\left(\mathrm{CO}_{2}\right)_{4}\right)_{3 / 2} \mathrm{X}\left(\mathrm{H}_{2} \mathrm{O}\right)_{2} \cdot n$ (solvent) ( $\mathrm{X}=$ $\mathrm{OH}$ or $\mathrm{Cl}$ ) combines several interesting aspects suited for practical applications. The framework is hydrothermally stable with iron(III) metal sites which are accessible upon departure of the coordinated water molecules. This MOF can be prepared easily and scaled-up under reflux in an environmentally friendly solvent, isopropanol. ${ }^{20}$ The preparations of nano to microscale MOFs are described and the performances of the materials prepared from different synthetic routes are compared by the authors. ${ }^{20}$ The material prepared with an environmentally friendly solvent possesses a rather high surface area $\left(S_{\mathrm{BET}}>1300 \mathrm{~m}^{2} \mathrm{~g}^{-1}\right)$, well within the range of the surface areas obtained using different synthesis conditions. MIL127 is therefore able to host biologically relevant cargoes ${ }^{21,22}$ and its iron(III) metal sites are beneficial for applications such as biomedicine, $^{22}$ separation $^{3 b}$ or catalysis. ${ }^{23}$

A series of mixed-metal MIL-127 materials with tailored properties is prepared. We primarily synthesized mixed-metal acetate building blocks using conditions adapted from previously reported protocols ${ }^{24}$ (Fig. 1 and Fig. S1, ESI $\dagger$ ) i.e., neutral mixed metal building blocks with general formula $\mathrm{Fe}^{\mathrm{III}}{ }_{2} \mathrm{M}^{\mathrm{II}} \mathrm{O}\left(\mathrm{H}_{2} \mathrm{O}\right)_{2}\left[\mathrm{O}_{2} \mathrm{C}-\mathrm{CH}_{3}\right]_{6} \cdot n \mathrm{H}_{2} \mathrm{O}$ (with $\mathrm{M}=\mathrm{Co}$ or Ni). Furthermore, a method for the preparation of $\mathrm{Fe} / \mathrm{Mg}$ acetate trimeric building blocks was developed (see ESI $\dagger$ for synthesis protocol details). The mixed metal acetate building blocks have then been used as precursors for the synthesis of the Fe/Co, Fe/Ni and Fe/Mg MIL-127 MOFs (Fig. 1 and $\mathrm{ESI} \dagger$ ) in environmentally friendly solvents (water, isopropanol) under reflux conditions. Such conditions allowed the easy upscaling of the preparation, producing materials with a space-time-yield of about $45 \mathrm{Kg} \mathrm{m}^{-3} \mathrm{~d}^{-1}$ (about $200 \mathrm{~g}$ could easily be obtained using a $5 \mathrm{~L}$ reactor). The formation of MIL127 solids is confirmed by X-ray powder diffraction (XRPD) (see Fig. S2-S5, ESI $\dagger$ ); Energy Dispersive X-ray spectroscopy (EDX) semi-quantitative analysis (see ESI $\dagger$ ) indicated that, in all cases, the controlled iron to metal(II) stoichiometry of $c a .2$ to 1 was obtained. Thermal gravimetric analysis (TGA), infrared (IR) spectroscopy and nitrogen sorption analysis were carried out to confirm the purity and integrity of the titled solids (Fig. S8-S10, ESI $\dagger$ ), all of them presenting similar surface areas $\left(\sim 1400 \mathrm{~m}^{2} \mathrm{~g}^{-1}\right)$ well within the expected range. It is worth mentioning that direct synthetic approaches using a 2 to 1 ratio of iron(III) and metal(II) salts (chlorides), using similar synthesis conditions, led to either amorphous or recrystallized linkers. This confirms the fact that metal(III) and metal(II) cations do not possess the same chemical reactivity, as expected from the differences in terms of their acidity and metal-ligand bond lability.

${ }^{57} \mathrm{Fe}$ Mössbauer spectroscopy data were collected at $300 \mathrm{~K}$ and $77 \mathrm{~K}$ on the mixed-metal MIL-127 MOFs as well as the corresponding starting mixed-metal acetate building block (see the spectra at $300 \mathrm{~K} \mathrm{Fig.} \mathrm{S13,} \mathrm{ESI} \dagger$ ). The quadrupolar spectra of both series, which consist of broadened and asymmetrical lines, can be described by means of at least 2 components attributed to HS $\mathrm{Fe}^{3+}$ species: the comparison of their hyperfine structure reveals some similarities with, however, clearly larger quadrupolar splitting values in the case of mixed-metal MIL-127 MOFs. This is due to the presence of the ligand, which distorts the symmetry around the Fe probe. Nevertheless, it can be concluded from those hyperfine structures that the starting mixed-metal building blocks remain stable during the synthesis. To further confirm that our method allows the preparation of mixed-metal cation MOFs at the microscopic level, in situ infrared spectroscopy analysis was carried out on MIL-127(Fe, Ni) (Fig. 2). NO adsorption experiments, monitored by in situ IR spectroscopy, have been performed since it has been well established that the $\nu(\mathrm{NO})$ bands of adsorbed nitrosyls depend on the nature and the oxidation state of the accessible cations. Room temperature NO adsorption on the MIL-127(Fe, Ni) sample activated at $423 \mathrm{~K}$ (Fig. 2a) revealed two $\nu$ (NO) bands centered at about 1874 and $1797 \mathrm{~cm}^{-1}$. The band at $1797 \mathrm{~cm}^{-1}$ indicates the presence of $\mathrm{NO}$ adsorbed on $\mathrm{Fe}^{2+}$ sites. $^{22}$ After activation at $503 \mathrm{~K}$, the intensity of this band slightly increased (Fig. 2a'). It is noteworthy that the sharp $\nu(\mathrm{NO})$ band at $1874 \mathrm{~cm}^{-1}$ has not been observed for pure iron based MOFs. Its wavenumber is close to that reported for NO interaction with the $\mathrm{Ni}^{2+}$ cations supported on metal oxides ${ }^{25}$ and therefore, it is assigned to NO interacting with coordinatively unsaturated $\mathrm{Ni}^{2+}$ sites. When NO was adsorbed at low temperature (Fig. 2(b) and ( $\left.b^{\prime}\right)$ ),

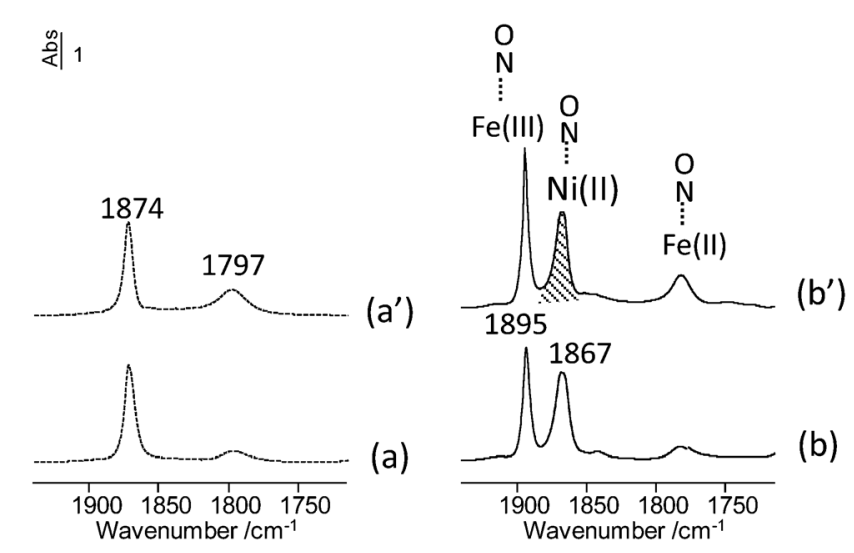

Fig. 2 IR spectra of MIL-127(Fe, Ni) recorded after introduction of an equilibrium pressure of $\mathrm{NO}(665 \mathrm{~Pa})$ at room temperature (dotted line) or low temperature (150 K, full line). Spectra (a) and (b): samples activated under secondary vacuum for 3 hours at $423 \mathrm{~K}$. Spectra $\left(a^{\prime}\right)$ and $\left(b^{\prime}\right)$, samples activated under secondary vacuum during 6 hours at $503 \mathrm{~K}$. 
an additional sharp band, observed at $1895 \mathrm{~cm}^{-1}$, can be assigned to the presence of NO weakly interacting with $\mathrm{Fe}^{3+} .22$ The concentration of NO adsorbed on the cation $(+\mathrm{II})$ species was estimated from their molar absorption coefficient (see Fig. S11 and S12, $\mathrm{ESI} \dagger)$. The number of $\mathrm{Fe}^{2+}$ sites is equal to about $70 \mu \mathrm{mol} \mathrm{g} \mathrm{g}^{-1}$ on MIL-127(Fe, Ni) activated to $423 \mathrm{~K}$, and $210 \mu \mathrm{mol} \mathrm{\textrm {g } ^ { - 1 }}$ on MIL-127(Fe, Ni) activated to $503 \mathrm{~K}$. However, the band intensity of $\mathrm{NO} / \mathrm{Fe}^{2+}$ remained much lower on MIL-127(Fe, Ni) than on MIL$127(\mathrm{Fe})^{22}$ whatever the activation temperature (Fig. 2(a) and $\left(\mathrm{a}^{\prime}\right)$ ) showing that the fraction of reduced Fe sites is low in the mixed metal MOFs (less than 0.08 after activation at $423 \mathrm{~K}$ ). By contrast, the number of $\mathrm{NO} / \mathrm{Ni}^{2+}$ species (band at $1874 \mathrm{~cm}^{-1}$ ) was much more important. This amount is equal to about $600-800 \mu \mathrm{mol} \mathrm{g}^{-1}$ for these activation temperatures which implies that most cation( $\left.+_{\text {II }}\right)$ sites were occupied by nickel. The global amount of $(\mathrm{Fe}, \mathrm{Ni})^{2+}$ was nearly constant after activation at 423 or $503 \mathrm{~K}$. Considering that the reducible character of the iron(III) metal sites in MIL-100(Fe) or MIL-127(Fe) was related to the departure of the anion $\left(\mathrm{F}^{-}\right.$or $\left.\mathrm{OH}^{-}\right)$compensating the positive charge of the framework, the low reducible character of MIL-127(Fe, Ni) is in agreement with the expected neutral framework in mixed metal frameworks due to the presence of a divalent compensating cation in the trimer units. One could therefore attribute here the presence of a weak residual amount of $\mathrm{Fe}(\mathrm{II})$ centers for the mixed cation solids to defects or surface sites.

Finally, to demonstrate the impact of the presence of the metal(II) cation within the porous architecture of the metal carboxylates, a combinatorial gas sorption analysis as well as adsorption microcalorimetry (see ESI $\dagger$ ) using $\mathrm{CO}_{2}$ and $\mathrm{CO}$ gas probes $^{26}$ were performed for the series of metal(II) substituted MIL-127 solids, which are also compared to the pure MIL-127(Fe). Fig. 3 shows the CO adsorption isotherms for MIL-127(Fe) and MIL-127(Fe, Ni) solids after activation to $423 \mathrm{~K}$ for 16 hours under vacuum. Indeed, previous studies have confirmed the presence of only Fe(III) metal sites upon activation at this temperature. ${ }^{22,30}$ It is clear that a rather low CO sorption capacity is observed in this pressure range for the pure iron solid, whereas the mixed $\mathrm{Fe} / \mathrm{Ni}$ MIL-127 solid activated under the same conditions possesses a six-fold larger sorption capacity.

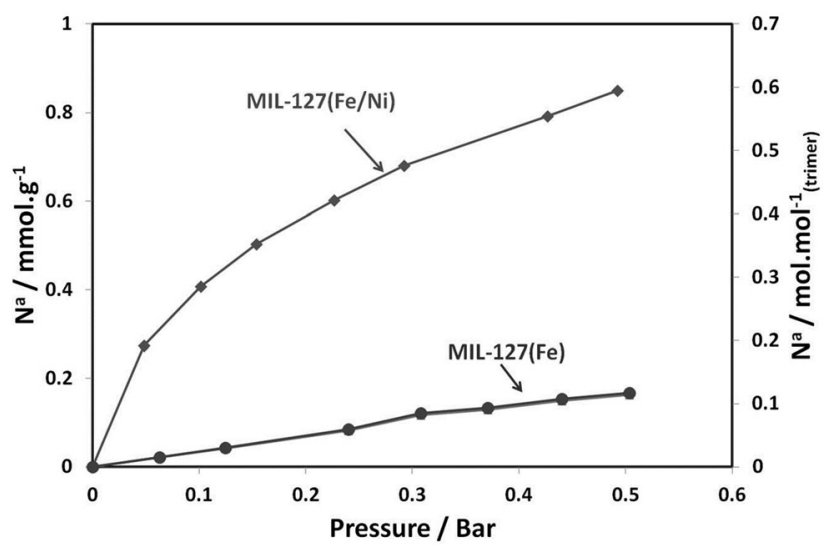

Fig. 3 Adsorption isotherms for carbon monoxide in MIL-127(Fe, Ni) and MIL-127(Fe) at $303 \mathrm{~K}$. Solids were activated at $423 \mathrm{~K}$ for $16 \mathrm{~h}$ under vacuum.
Upon activation at higher temperature (473 K), a clear dependence of the nature of the metal(II) cation is noticeable for the polar CO probe (Fig. S15, ESI $\dagger$ ). Activation to $473 \mathrm{~K}$ can lead to the formation of a significant amount of iron(II) sites. ${ }^{22,27,28}$ One can therefore deduce an affinity ranking for $\mathrm{CO}$ for the various divalent species with the trend: $\mathrm{Ni}^{2+}>\mathrm{Co}^{2+}>\mathrm{Fe}^{2+}>\mathrm{Mg}^{2+}$, in agreement with the differences in the enthalpies of adsorption that lie from about -30 to $-50 \mathrm{~kJ} \mathrm{~mol}^{-1}$ at low coverage (Fig. S15a, ESI $\dagger$ ). This order of affinity for the metal(II) sites and $\mathrm{CO}$ is in agreement with previous data reported for CPO-27 or MOF-74. ${ }^{29}$ Indeed, this can be rationally explained by the electronegativity of these metals, following what is commonly observed through the back donation effect between metal(II) sites and unsaturated molecules. Whilst increasing the activation temperature of the MIL-127(Fe) solid leads to an increase in the CO adsorption capacity (see Fig. 3 and Fig. S15b, ESI $\dagger$ ), this is not the case for the mixed valence materials. This trend is consistent with the IR data, which show for MIL-127(Fe) an increase of $\mathrm{Fe}^{2+}$ only with increasing activation temperature whilst for MIL-127(Fe, $\mathrm{Ni}$ ) the amount of $(\mathrm{Fe}, \mathrm{Ni})^{2+}$ is not sensitive to the activation temperature. This suggests an easier availability of the unsaturated metal(II) sites of the mixed metal MIL-127 solids, since their accessibility only requires the departure of the coordinated solvent molecules, which generally occurs at lower temperature than the higher activation temperature necessary to create unsaturated metal(II) sites in the case of the pure iron MIL-127 (473 K). This represents an added value for practical applications, which often prefer low energetic activation conditions. Nonetheless, no significant differences are observed at low coverage $\left(<1\right.$ bar) for $\mathrm{CO}_{2}$ (Fig. S14, ESI $\dagger$ ). Finally, this strategy can be extended to other trimeric building unit based MOFs such as the highly flexible metal terephthalate MIL- $88 \mathrm{~B}^{7}$ or the rigid mesoporous trimesate MIL- $100^{31}$ based on the Fe/Ni building block, which were successfully synthesized using our strategy (see synthesis and characterization details in the ESI $\dagger$ ) as well as other mixed metal MOFs reported during the course of our study. ${ }^{32}$

Here, we firstly report the environmentally-friendly and scalable preparation of mixed iron(III)/metal(II) ( $\mathrm{M}=\mathrm{Ni}, \mathrm{Co}, \mathrm{Mg}$ ) acetate building units for the design of mixed metal Fe(III)/M(II) ( $\mathrm{M}=\mathrm{Co}$, $\mathrm{Ni}, \mathrm{Mg}$ ) porous MOFs of interest with a controlled iron/metal stoichiometry. IR spectroscopy and adsorption studies both confirm a direct accessibility of both Fe(III) and M(II) Lewis acid sites. Further studies will focus on the establishment of a library of mixed-metal MOFs and the analysis of their properties for various relevant applications.

The research leading to these results has received funding from the European Community's Seventh Framework Program (FP7/2007-2013) under grant agreement no. 228862. The authors would also like to thank Antoine Tissot and Nathalie Guillou for their valuable help.

\section{Notes and references}

1 Themed issues: Chem. Soc. Rev., 2014, 43, 5403-6176; Chem. Rev., 2012, 112, 673-1268; CrystEngComm, 2015, 17, 695.

2 J. J. Low, A. I. Benin, P. Jakubczak, J. F. Abrahamian, S. A. Faheem and R. R. Willis, J. Am. Chem. Soc., 2009, 15834. 
3 (a) Y.-K. Seo, J. W. Yoon, J. S. Lee, Y. K. Hwang, C.-H. Jun, J.-S. Chang, S. Wuttke, P. Bazin, A. Vimont, M. Daturi, S. Bourrelly, P. L. Llewellyn, P. Horcajada, C. Serre and G. Férey, Adv. Mater., 2012, 24, 806; (b) J. Yoon, Y. K. Seo, Y. Hwang, J. S. Chang, H. Leclerc, S. Wuttke, P. Bazin, A. Vimont, M. Daturi, E. Bloch, P. Llewellyn, C. Serre, P. Horcajada, J. M. Grenèche, A. Rodrigues and G. Férey, Angew. Chem., Int. Ed., 2010, 49, 5949.

4 (a) A. Dhakshinamoorthy, M. Alvaro, H. Chevreau, P. Horcajada, T. Devic, C. Serre and H. Garcia, Catal. Sci. Technol., 2012, 2, 324; (b) A. Dhakshinamoorthy, M. Alvaro, Y. K. Hwang, Y.-K. Seo, A. Corma and H. Garcia, Dalton Trans., 2011, 40, 10719.

5 P. Horcajada, T. Chalati, C. Serre, B. Gillet, C. Sebrie, T. Baati, J. F. Eubank, D. Heurtaux, P. Clayette, C. Kreuz, J. S. Chang, Y. K. Hwang, V. Marsaud, P. N. Bories, L. Cynober, S. Gil, G. Férey, P. Couvreur and R. Gref, Nat. Mater., 2010, 9, 172.

6 T. R. Whitfield, X. Wang, L. Liu and A. J. Jacobson, Solid State Sci., 2005, 7, 1096.

7 S. Surblé, C. Serre, C. Mellot-Draznieks, F. Millange and G. Férey, Chem. Commun., 2006, 284.

8 P. Horcajada, S. Surblé, C. Serre, D.-Y. Hong, Y.-K. Seo, J.-S. Chang, J.-M. Grenèche, I. Margiolaki and G. Férey, Chem. Commun., 2007, 2820.

9 S. Bauer, C. Serre, T. Devic, P. Horcajada, J. Marrot, G. Férey and N. Stock, Inorg. Chem., 2008, 47, 7568.

10 D. Yuan, R. B. Getman, Z. Wei, R. Q. Snurr and H.-C. Zhou, Chem. Commun., 2012, 48, 3297-3299.

11 S. B. Choi, M. J. Seo, M. Cho, Y. Kim, M. K. Jin, D.-Y. Jung, J.-S. Choi, W.-S. Ahn, J. L. C. Rowsell and J. Kim, Cryst. Growth Des., 2007, 7, 2290-2293.

12 A. Fateeva, S. Devautour-Vinot, N. Heymans, T. Devic, J.-M. Grenèche, S. Wuttke, S. Miller, A. Lago, C. Serre, G. De Weireld, G. Maurin, A. Vimont and G. Férey, Chem. Mater., 2011, 23, 4641.

13 K. Wang, D. Feng, T.-F. Liu, J. Su, S. Yuan, Y.-P. Chen, M. Bosch, X. Zou and H.-C. Zhou, J. Am. Chem. Soc., 2014, 136, 13983.

14 (a) F. Nouar, T. Devic, H. Chevreau, N. Guillou, E. Gibson, G. Clet, M. Daturi, A. Vimont, J.-M. Grenèche, M. I. Breeze, R. I. Walton, P. L. Llewellyn and C. Serre, Chem. Commun., 2012, 48, 10237; (b) A. D. Burrows, CrystEngComm, 2011, 13, 3623.

15 J. D. Evans, C. J. Sumby and C. J. Doonan, Chem. Soc. Rev., 2014, 43, 5933.

16 C. Serre, F. Millange, S. Surblé and G. Férey, Angew. Chem., Int. Ed., 2004, 43, 6285.
17 V. Guillerm, S. Gross, C. Serre, T. Devic, M. Bauer and G. Férey, Chem. Commun., 2010, 46, 767.

18 S. Surblé, F. Millange, C. Serre, G. Férey and R. I. Walton, Chem. Commun., 2006, 1518.

19 Y. Liu, J. F. Eubank, A. J. Cairns, J. Eckert, V. C. Kravtsov, R. Luebke and M. Eddaoudi, Angew. Chem., Int. Ed., 2007, 46, 3278.

20 H. Chevreau, et al., J. Mater. Chem., submitted.

21 D. Cunha, M. Ben Yahia, S. Hall, S. R. Miller, H. Chevreau, E. Elkaïme, G. Maurin, P. Horcajada and C. Serre, Chem. Mater., 2013, 25, 2767.

22 J. F. Eubank, P. S. Wheatley, G. Lebars, A. C. Mckinlay, H. Leclerc, P. Horcajada, M. Daturi, A. Vimont, R. E. Morris and C. Serre, APL Mater., 2014, 2, 124112.

23 C. Serre, P. Horcajada, G. Férey, A. Vimont, M. Daturi, P.L. Llewellyn, Y.K. Hwang, J.-W. Yoon, J. S. Chang, 106660/FR PCT/FR2010/000402 $(28 / 05 / 2010)$.

24 H. Vrubel, T. Hasegawa, E. de Oliveira and F. S. Nunes, Inorg. Chem. Commun., 2006, 9, 208.

25 K. I. Hadjiivanov, Catal. Rev.: Sci. Eng., 2000, 42(1\&2), 71.

26 (a) H. Sato, W. Kosaka, R. Matsuda, A. Hori, Y. Hijikata, R. V. Belosludov, S. Sakaki, M. Takata and S. Kitagawa, Science, 2013, 343(6167), 167; (b) E. D. Bloch, M. R. Hudson, J. A. Mason, S. Chavan, V. Crocella, J. D. Howe, K. Lee, A. L. Dzubak, W. L. Queen, J. M. Zadrozny, S. J. Geier, L.-C. Lin, L. Gagliardi, B. Smit, J. B. Neaton, S. Bordiga, C. M. Brown and J. R. Long, J. Am. Chem. Soc., 2014, 136, 10752.

27 C. Serre, P. Horcajada, G. Férey, A. Vimont, M. Daturi, Y. K. Hwang, J. W. Yoon, J. S. Chang use of a porous crystalline hybrid solid as a nitrogen oxide reduction catalyst and devices, PCT/FR2010/000402 filed 28/05/2010.

28 M. Maes, M. Trekels, M. Boulhout, S. Schouteden, F. Vermoortele, L. Alaerts, D. Heurtaux, Y.-K. Seo, Y. K. Hwang, J.-S. Chang, I. Beuroies, R. Denoyel, K. Temst, A. Vantomme, P. Horcajada, C. Serre and D. E. De Vos, Angew. Chem., Int. Ed., 2011, 50, 4210.

29 L. Valenzano, B. Civalleri, K. Sillar and J. Sauer, J. Phys. Chem. C, 2011, 115, 21777.

30 S. Wuttke, P. Bazin, A. Vimont, C. Serre, Y.-K. Seo, Y. K. Hwang, J.-S. Chang, G. Férey and M. Daturi, Chem. - Eur. J., 2012, 18, 11959.

31 G. Férey, C. Serre, C. Mellot-Draznieks, F. Millange, S. Surblé, J. Dutour and I. Margiolaki, Angew. Chem., Int. Ed., 2004, 43, 6296.

32 D. Feng, K. Wang, Z. Wei, Y.-P. Chen, C. M. Simon, R. K. Arvapally, R. L. Martin, M. Bosch, T.-F. Liu, S. Fordham, D. Yuan, M. A. Omary, M. Haranczyk, B. Smit and H.-C. Zhou, Nat. Commun., 2014, 5, 5723. 